\title{
The Danish Melanoma Database
}

This article was published in the following Dove Press journal:

Clinical Epidemiology

25 October 2016

Number of times this article has been viewed

\section{Lisbet Rosenkrantz Hölmich' \\ Siri Klausen ${ }^{2}$ \\ Eva Spaun ${ }^{3}$ \\ Grethe Schmidt ${ }^{4}$ \\ Dorte $\mathrm{Gad}^{5}$ \\ Inge Marie Svane ${ }^{6,7}$ \\ Henrik Schmidt ${ }^{8}$ \\ Henrik Frank Lorentzen ${ }^{9}$ \\ Else Helene Ibfelt ${ }^{10}$ \\ 'Department of Plastic Surgery, \\ ${ }^{2}$ Department of Pathology, \\ Herlev-Gentofte Hospital, University \\ of Copenhagen, Herlev, Institute of \\ Pathology, Aarhus University Hospital, \\ Aarhus, ${ }^{4}$ Department of Plastic \\ and Reconstructive Surgery, Breast \\ Surgery and Burns, Rigshospitalet - \\ Glostrup, University of Copenhagen, \\ Copenhagen, ${ }^{5}$ Department of Plastic \\ Surgery, Odense University Hospital, \\ Odense, ${ }^{6}$ Center for Cancer Immune \\ Therapy, Department of Hematology, \\ ${ }^{7}$ Department of Oncology, \\ Herlev-Gentofte Hospital, University \\ of Copenhagen, Herlev, ${ }^{8}$ Department \\ of Oncology, ${ }^{9}$ Department of \\ Dermatology, Aarhus University \\ Hospital, Aarhus, ${ }^{10}$ Registry Support \\ Centre (East) - Epidemiology and \\ Biostatistics, Research Centre for \\ Prevention and Health, Glostrup - \\ Rigshospitalet, University of \\ Copenhagen, Glostrup, Denmark}

Correspondence: Lisbet Rosenkrantz Hölmich

Department of Plastic Surgery,

Herlev-Gentofte Hospital, University of

Copenhagen, Herlev Ringvej 75, 2730

Herlev, Denmark

Tel +45 38682588

Fax + 4538683855

Email lisbet.rosenkrantz.hoelmich@ regionh.dk
Aim of database: The aim of the database is to monitor and improve the treatment and survival of melanoma patients.

Study population: All Danish patients with cutaneous melanoma and in situ melanomas must be registered in the Danish Melanoma Database (DMD). In 2014, 2,525 patients with invasive melanoma and 780 with in situ tumors were registered. The coverage is currently $93 \%$ compared with the Danish Pathology Register.

Main variables: The main variables include demographic, clinical, and pathological characteristics, including Breslow's tumor thickness, \pm ulceration, mitoses, and tumor-node-metastasis stage. Information about the date of diagnosis, treatment, type of surgery, including safety margins, results of lymphoscintigraphy in patients for whom this was indicated (tumors > T1a), results of sentinel node biopsy, pathological evaluation hereof, and follow-up information, including recurrence, nature, and treatment hereof is registered. In case of death, the cause and date are included. Currently, all data are entered manually; however, data catchment from the existing registries is planned to be included shortly.

Descriptive data: The DMD is an old research database, but new as a clinical quality register. The coverage is high, and the performance in the five Danish regions is quite similar due to strong adherence to guidelines provided by the Danish Melanoma Group. The list of monitored indicators is constantly expanding, and annual quality reports are issued. Several important scientific studies are based on DMD data.

Conclusion: DMD holds unique detailed information about tumor characteristics, the surgical treatment, and follow-up of Danish melanoma patients. Registration and monitoring is currently expanding to encompass even more clinical parameters to benefit both patient treatment and research.

Keywords: melanoma, malignant melanoma, clinical database, quality database, melanoma registry, Denmark

\section{Introduction}

The Danish Melanoma Group (DMG), which is part of the Danish Multidisciplinary Cancer Groups, ${ }^{1}$ has since 1985 on a national basis collected detailed clinical, surgical, pathological, and follow-up information on Danish patients suffering from cutaneous melanoma, including in situ lesions, in the Danish Melanoma Database (DMD). The DMG is an organization focusing on improving care for Danish melanoma patients. All medical specialists with interest in melanoma treatment are involved, and organization of the database, supporting research, and developing clinical guidelines are important parts of the activity. ${ }^{2}$ Until 2011 , the database was a private initiative, driven 
by dedicated specialists and without stable funding. In 2011, the database was approved as a clinical quality database under the support of the Danish Regions' Clinical Quality Program, and the first annual quality report was published in 2014 based on 2013 data. Since 2011, data registration has been performed online, and data from 2000 and onward have been entered in the current version. A revision of the registration forms/online modules has just been completed, and the nature and number of quality indicators included in the annual reports are an evolving process. In previous publications, slightly different names for the database have been used over the years: DMG Database, Danish Melanoma Registry, and now the DMD.

Cutaneous melanoma is a potentially deadly disease, generally with a high capacity for metastatic spread. The prognosis primarily depends on tumor thickness at the time of diagnosis. Ulceration of the epithelium and mitotic activity within the dermal component of the tumor along with spread to the draining sentinel node(s) are the other most important negative prognostic variables. ${ }^{3}$ More than half of the tumors currently diagnosed are thin $(\leq 1.00 \mathrm{~mm})$ with a very good prognosis. ${ }^{4}$ Treatment of melanoma is surgical with local wide excision to secure safety margins; sentinel node staging is performed for tumors with a $\geq 10 \%$ risk of (micro)metastases to regional lymph nodes ( $\mathrm{T} 1 \mathrm{~b}$ tumors or higher: thickness $>1.00 \mathrm{~mm}$ or if ulceration or mitotic activity is present). ${ }^{5}$ Radical lymph node dissection is generally performed in case of spread to the regional lymph nodes. Solitary metastases are generally treated surgically; however, when this is no longer feasible, systemic treatment is offered. ${ }^{2}$

\section{Aim of database}

The aim of the database is to monitor and thereby improve treatment and survival for melanoma patients. More specifically, the purpose of the DMD is to systematically collect key clinical parameters on all incident cases of invasive or in situ melanoma in Denmark for health care monitoring, quality improvement, and research.

\section{Study population}

The study population includes all Danish patients with cutaneous melanoma, including in situ lesions. New patients are registered at the time of diagnosis; for patients already in the database, follow-up information including recurrence is recorded, in general until 5 years after initial treatment or last recurrence. In case of late recurrence, the registration is resumed. The incidence of melanoma has increased at the rate of $4 \%-5 \%$ per year, and in situ lesions perhaps even more; however, the preliminary result for 2015 for the first time in the history of the database shows a decrease of $4.2 \%$ for invasive melanoma, while the in situ lesions still increase with 3.6\%. ${ }^{6}$ The 2014 annual report included 2,525 patients with invasive melanoma and 780 with in situ lesions, ${ }^{4}$ corresponding to a crude incidence of $44.6 / 100,000$ and 13.8/100,000, respectively, and in the 2013 report, 2,325 patients had invasive melanoma and 505 had in situ melanomas. The database has included 30,000 patients since 1985 .

Table I Main variables included in the DMD

\begin{tabular}{|c|c|}
\hline Category & Variable \\
\hline Demographic data & $\begin{array}{l}\text { Sex } \\
\text { Age at diagnosis } \\
\text { Familial melanoma } \\
\text { Presence of dysplastic/atypical nevi }\end{array}$ \\
\hline Clinical tumor data & $\begin{array}{l}\text { Location of tumor ( } 53 \text { different locations) } \\
\text { Largest diameter of tumor } \\
\text { Specific clinical tumor characteristics }\end{array}$ \\
\hline $\begin{array}{l}\text { Primary diagnosis } \\
\text { Definitive surgery }\end{array}$ & $\begin{array}{l}\text { Type and date of biopsy } \\
\text { Date of surgery } \\
\text { Excision margin } \\
\text { Method for closure of defect } \\
\pm \text { Sentinel node biopsy }\end{array}$ \\
\hline $\begin{array}{l}\text { Pathology data on the } \\
\text { primary tumor }\end{array}$ & $\begin{array}{l}\text { Melanoma type } \\
\text { Specific pathological tumor characteristics, } \\
\text { including presence of ulceration and mitoses } \\
\text { Tumor thickness in mm (two decimals) and } \\
\text { Clark's level } \\
\pm \text { Satellites } \\
\pm \text { Free resection margins } \\
\text { Uncertain whether malignant or benign tumor } \\
\text { Insufficient material for diagnosis }\end{array}$ \\
\hline $\begin{array}{l}\text { TNM classification } \\
\text { Data from }\end{array}$ & \\
\hline $\begin{array}{l}\text { lymphoscintigraphy } \\
\text { Data from sentinel } \\
\text { node biopsy }\end{array}$ & $\begin{array}{l}\text { tracer, result } \\
\text { Date of surgery, } \pm \text { use of patent blue, activity } \\
\text { and stain in removed nodes, remaining activity } \\
\text { in region }\end{array}$ \\
\hline Recurrence & $\begin{array}{l}\text { Were metastases detected at the time of } \\
\text { primary diagnosis with a known primary tumor? } \\
\text { Location of recurrence }\end{array}$ \\
\hline $\begin{array}{l}\text { Treatment of } \\
\text { recurrence }\end{array}$ & $\begin{array}{l}\text { Date and nature of operation } \\
\text { Results of lymph node dissection (number of } \\
\text { nodes with metastases and number of nodes } \\
\text { removed) } \\
\text { Referral to oncological treatment }\end{array}$ \\
\hline $\begin{array}{l}\text { Follow-up } \\
\text { information }\end{array}$ & $\begin{array}{l}\text { Date and status at the time of follow-up ( } \pm \text { sign } \\
\text { of recurrence) } \\
\text { In case of recurrence, who/how suspected/ } \\
\text { detected } \\
\text { Information about future plan for follow-up }\end{array}$ \\
\hline Off-study information & $\begin{array}{l}\text { Date of last visit } \\
\text { Date and cause of death if known } \\
\pm \text { Autopsy performed }\end{array}$ \\
\hline
\end{tabular}

$\overline{\text { Abbreviations: DMD, Danish Melanoma Database; TNM, tumor-node-metastasis. }}$ 


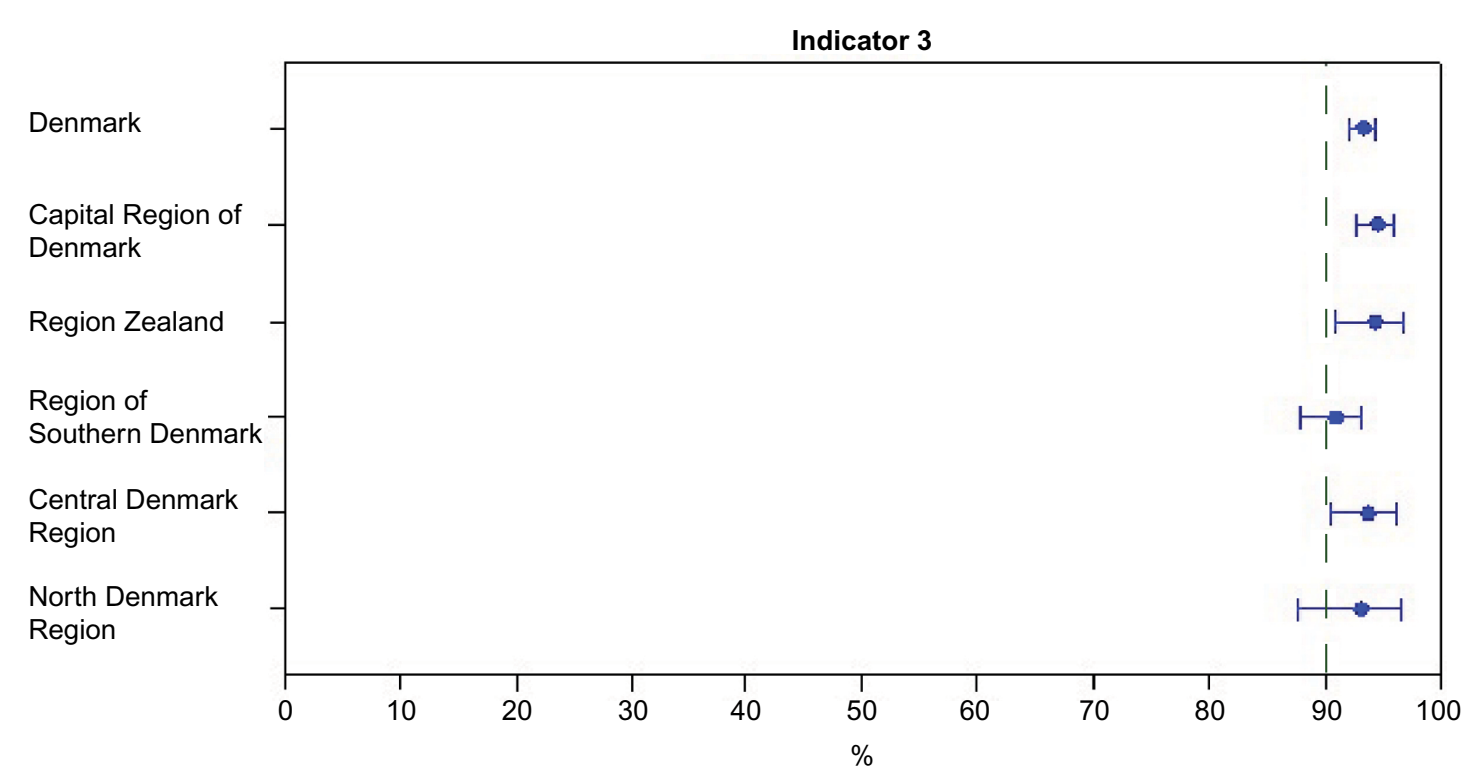

Figure I Regional performance regarding indicator 3 (excisional margins according to guidelines).

Notes: The blue dots present the result for each region and Denmark as a whole (with $95 \%$ confidence limits) for quality indicator 3 : the fraction of tumors where excisional margins are performed according to the guidelines. The vertical dotted line shows the standard set as an aim of acceptance for the indicator by the DMD steering committee. Data from Dansk Melanom Database. ${ }^{4}$

Abbreviation: DMD, Danish Melanoma Database.

\section{Main variables}

The main variables are listed in Table 1. The pathologist performs the primary entry to the DMD. All relevant tumor characteristics are registered. The Department of Plastic Surgery is responsible for recording the treatment. Currently, physicians in primary health care have removed $38 \%$ of tumors at the time of referral. ${ }^{4}$ The following information is recorded at the first visit: brief information on the history, any familial melanoma, location and clinical description of the tumor, and details of the bioptic basis for the diagnosis (if the tumor is still present, an excisional biopsy is performed at this stage). Later, data on the definite surgery and sentinel node biopsy procedure (if performed) are registered, including information on method and results of lymphoscintigraphy. Pathological evaluation of the sentinel node(s) is recorded with detailed information about location and size of metastases. The tumor-node-metastasis stage is recorded. In case of metastases at the time of diagnosis or later, the clinical information on nature of and location of metastases is recorded, as well as overall information about treatment for this. Follow-up information including status at the time of follow-up (recurrence free, [sign of] recurrence, etc) is entered. The DMD currently does not hold data on outcomes of systemic treatment; these are registered in a private oncologic research database. Information about adjuvant treatment has been added by January 2016. In case of death, the patient is registered off study with date and cause of death. All data have so far been entered manually; however, considerable
Table 2 Current key indicators for the DMD

\begin{tabular}{lll}
\hline $\begin{array}{l}\text { Indicator } \\
\text { number }\end{array}$ & $\begin{array}{l}\text { Proportion with required information } \\
\text { about }\end{array}$ & Aim \\
\hline I & TNM stage & $>90 \%$ \\
2 & $\begin{array}{l}\text { Excisional margin for treatment of primary tumor } \\
\text { If total excisional margin was performed according }\end{array}$ & $>95 \%$ \\
3 & $\begin{array}{l}\text { to guidelines } \\
\text { If sentinel lymph node biopsy was performed in }\end{array}$ & $>85 \%$ \\
4 & $\begin{array}{l}\text { tumors } \geq \text { TIb } \\
\text { Breslow's tumor thickness }\end{array}$ & $>97 \%$ \\
5 & Ulceration of the tumor $( \pm)$ & $>97 \%$ \\
6 & Dermal mitoses $( \pm)$ & $>97 \%$ \\
8 & Size and location of metastases within metastatic & $>97 \%$ \\
9 & sentinel lymph nodes & $>97 \%$ \\
10 & $\begin{array}{l}\text { Metastases }( \pm) \text { in sentinel lymph nodes } \\
\text { At least ten lymph nodes removed at axillary }\end{array}$ & $>90 \%$ \\
\hline
\end{tabular}

Abbreviations: DMD, the Danish Melanoma Database; TNM, tumor-node-metastasis.

data catchment from the existing registries (the Danish Pathology Register, the Danish Civil Registration System, and the National Hospital Discharge Register) is planned to commence during 2016.

\section{Data quality}

Prior to the online registration, all registration forms were entered into a database centrally, and missing variables were identified and corrections pursued. After the electronic online registration was introduced, lists of missing data have been produced on key variables, and this list is still expanding in order to include all indicators. 


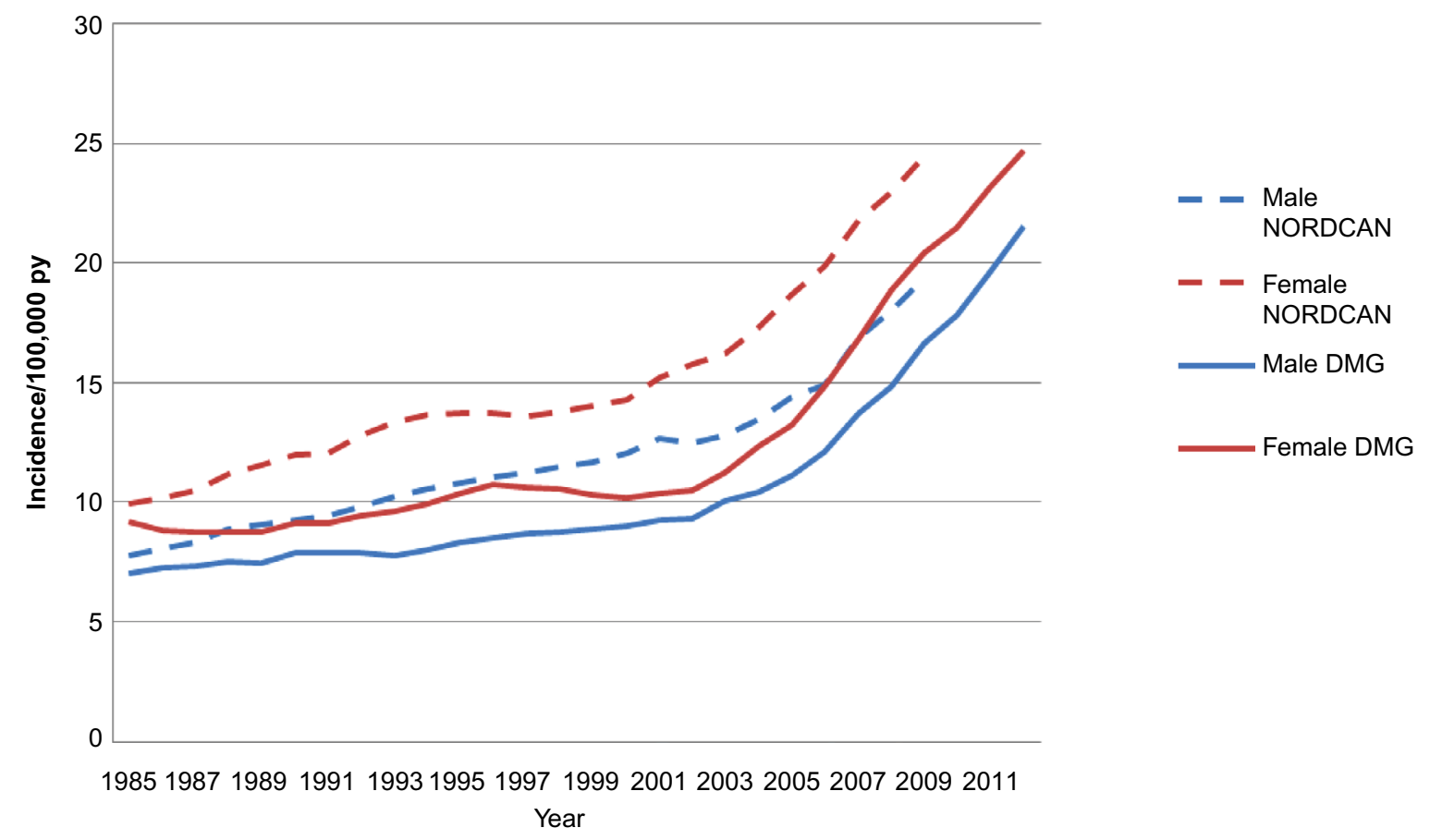

Figure 2 Age-standardized incidence rates from the DMD (full lines) compared with age-standardized incidence rates from the NORDCAN (dotted lines).

Notes: aNORDCAN is a collaboration of the cancer registries in the Nordic countries. Data, which can be accessed online in an open version, are derived from the national cancer registries and slightly modified to be comparable. Data from Engholm et al. ${ }^{17}$

Abbreviations: DMD, the Danish Melanoma Database; py, per year; DMG, Danish Melanoma Group.

In the annual quality reports, performance on selected key indicators is presented by region and by department. Figure 1 is an example of the small regional variation observed for the current key indicators (Table 2). The annual quality results give a very strong incitement for improving registration. Generally, data about on-study information, clinical stage at diagnosis, definite treatment, and the concurrent pathological variables are registered in $94.5 \%-98.7 \%$ of the cases. ${ }^{4}$ Reporting of recurrence has not yet been included in the quality report, but we know that the quality of data on this is still suboptimal, however improving over time. No formal studies on the exact numbers of missing variables have been made. The coverage of all melanomas is now evaluated by comparison to the Danish Pathology Register, ${ }^{7}$ and the national coverage is $93 \%{ }^{4}$ In a recent scientific study on the incidence from 1985 to 2012, data from the DMD were compared with melanomas registered in the Danish Cancer Registry. ${ }^{6}$ This study revealed that the DMD over the years has constantly captured $\sim 80 \%-90 \%$ of cases (Figure 2 ). ${ }^{6}$ The Cancer Registry does not hold detailed information about location of tumor, tumor characteristics of prognostic significance (thickness, ulceration, mitoses), treatment, recurrence, follow-up, and in situ cancers and has no information about family history.

\section{Follow-up}

Follow-up is primarily clinical and includes examination of the operated area and the rest of the patient's skin and thorough palpation of lymph node regions as well as the area in between, searching for in-transit metastases (lymphatic spread is the most common route for metastases in most cases). When internal metastases are suspected, imaging (primarily positron emission tomography-computed tomography) is applied, and ultrasonography-guided fine needle aspiration is the method of choice for diagnosis. The use of imaging has increased, but not systematically, in patients with intermediate to thick tumors where risk of recurrence is not negligible and also without actual suspicion of metastases.

The follow-up program has been revised and fully implemented (by January 2016) toward a more intensive program for patients with the poorest prognosis and a less frequent follow-up for patients with better prognosis. ${ }^{8}$ Patients with T1a tumors and without highly increased risk of second melanomas will not be followed up, except for a visit of 3 months postoperatively. Patients with tumors of intermediate thickness, with a negative sentinel node examination (stage IB, IIA), will be followed up clinically as described with visits twice annually for 5 years. Patients with thick tumors and patients with regional metastases at the time of 
diagnosis (clinical stages IIB, IIC, III) will be followed up with a clinical examination of four times a year for the first 2 years and then twice a year for the next 3 years. Positron emission tomography-computed tomography will be performed after 6 months, 12 months, 24 months, and 36 months on a routine basis. In all stages, further examinations, imaging, etc will be applied when indicated. Besides status at the time of follow-up (recurrence free, [sign of] recurrence, etc), database data about follow-up will also include information about who suspected the recurrence, how it was diagnosed (clinically, due to symptoms, or with use of imaging), and which kind of imaging was used. The new follow-up program will be monitored in a prospective study. Within the next year, linkage to the Danish Civil Registry will be implemented to achieve complete follow-up for survival on all registered melanoma patients.

\section{Examples of research}

Data from the DMD have been used for epidemiological, clinical, genetic, pathological, and molecular studies. ${ }^{6,9-14}$ The recent study on the development in incidence is a good example of an epidemiological study with use of the data, and this allows for monitoring of the development in incidence and mortality (a study in preparation) over time. ${ }^{6}$ Advanced molecular and pathology studies have used detailed information from the DMD and provided important new knowledge on tumor profiles and pathogenesis. ${ }^{11-14}$ In Denmark, we have unique possibilities for high-quality register-based scientific studies because all inhabitants are assigned a unique personal identification number (civil personal registration number). With this number, it is possible to link to a number of validated health and administrative registries.

\section{Administrative issues and funding}

The Danish Health Authority and the Danish Data Protection Agency have approved the DMD, and the registration is mandatory. The DMD is funded by the Danish Regions ${ }^{15}$ and is administered by the Danish Clinical Registries (RKKP), ${ }^{16}$ which is the Danish Regions' Clinical Quality Program. The budget allows for the daily maintenance and administration of the database, but not for research. The participating departments collect and report data as part of the clinical work without additional financial support. Budget and other report drafting for the Danish Regions is maintained with the help from the Registry Support Centre (East) - Clinical Quality Improvement \& Health Informatics.

\section{Conclusion}

The DMD is an old database, but new as a clinical quality register under the Danish Regions' Clinical Quality Program.
Registration is integrated in the daily clinical activities in pathology departments as well as in the plastic surgery and oncology departments, when responsible for follow-up. The DMD holds unique detailed information about tumor characteristics, surgical treatment, and follow-up. The production of the annual quality reports has clarified the need for revision of the registration forms/electronic modules to ensure the ability to expand the monitoring to encompass even more clinical parameters. In this way, also the basis for research in the field is improved.

\section{Acknowledgments}

This article was funded by the Program for Clinical Research Infrastructure established by the Lundbeck Foundation and the Novo Nordisk Foundation and administered by the Danish Regions.

The electronic database is developed and managed by Aleksandar Jovanovic of Carma Group ApS, and without his steady strive for completeness, the database would not be in the current good shape. The DMG includes dedicated specialists all collaborating for the benefit of the melanoma patients. The DMD is controlled by the Steering Committee, which includes the members of the DMG's Board as well as specialists in plastic surgery and pathology from regions, not represented in the Board. The annual reports are produced by Registry Support Centre (East) - Epidemiology and Biostatistics where data managers and epidemiologists in collaboration with the DMG present the data.

\section{Disclosure}

The DMD cooperates with the medical industry in development and research. This includes testing of oncologic products, clinical tests, participation in advisory boards, meetings, and teaching. There are no financial disclosures in relation to this work. The authors report no other conflicts of interest in this work

\section{References}

1. Danish Multidisciplinary Cancer Groups (DMCG.dk) [homepage on the Internet]. Available from: www.dmcg.dk. Accessed March 13, 2016.

2. Danish Melanoma Group [homepage on the Internet]. Available from: www.melanoma.dk. Accessed May 2, 2016

3. Balch CM, Gershenwald JE, Soong SJ, et al. Final version of 2009 AJCC melanoma staging and classification. J Clin Oncol. 2009; 27(36):6199-6206.

4. Dansk Melanom Database [webpage on the Internet]. National Årsrapport 2014. Available from: https://www.sundhed.dk/content/ cms/30/57130_\%C3\%A5rsrapport_melanomer_2014_endelig.pdf. Accessed July 29, 2015.

5. Chakera AH, Hesse B, Burak Z, et al; European Association of Nuclear Medicine-European Organisation for Research. EANM-EORTC general recommendations for sentinel node diagnostics in melanoma. Eur $J$ Nucl Med Mol Imaging. 2009;36(10):1713-1742. 
6. Helvind NM, Hölmich LR, Smith S, et al. Incidence of in situ and invasive melanoma in Denmark from 1985 through 2012 a national database study of 24059 melanoma cases. JAMA Dermatol. 2015;151(10): 1087-1095.

7. Bjerregaard B, Larsen OB. The Danish pathology register. Scand J Public Health. 2011;39(7 suppl):72-74.

8. Sundhedsstyrelsen [The Danish Health Authority] [webpage on the Internet]. Opfølgningsprogram for modermærkekræft (melanom) [Follow-up program for melanoma patients]. Available from: https:// sundhedsstyrelsen.dk/da/udgivelser/2015/ /media/06A4C4DB820A4 9F19311C5879672BE7D.ashx. Accessed May 2, 2016. Danish.

9. Chakera AH, Drzewiecki KT, Eigtved A, Juhl BR. Sentinel node biopsy for melanoma: a study of 241 patients. Melanoma Res. 2004;14(6):521-526.

10. Jensen TO, Schmidt H, Møller HJ, et al. Macrophage markers in serum and tumor have prognostic impact in American Joint Committee on Cancer stage I/II melanoma. J Clin Oncol. 2009;27(20):3330-3337.

11. Weischer M, Heerfordt IM, Bojesen SE, et al. CHEK2 $* 1100$ delC and risk of malignant melanoma: Danish and German studies and metaanalysis. J Invest Dermatol. 2012;132(2):299-303.
12. Lade-Keller J, Riber-Hansen R, Guldberg P, Schmidt H, Hamilton-Dutoit SJ, Steiniche T. E- to N-cadherin switch in melanoma is associated with decreased expression of phosphatase and tensin homolog and cancer progression. Br J Dermatol. 2013;169(3):618-628.

13. Antonio N, Bønnelykke-Behrndtz ML, Ward LC, et al. The wound inflammatory response exacerbates growth of pre-neoplastic cells and progression to cancer. EMBO J. 2015;34(17):2219-2236.

14. Wadt KA, Aoude LG, Krogh L, et al. Molecular characterization of melanoma cases in Denmark suspected of genetic predisposition. PLoS One. 2015;10(3):e0122662.

15. Danish Regions [homepage on the Internet]. Available from: http:// www.regioner.dk. Accessed March 14, 2016.

16. The Danish Clinical Registries (RKKP) [homepage on the Internet]. Available from: http://www.rkkp.dk. Accessed March 14, 2016.

17. Engholm G, Ferlay J, Christensen N, et al [homepage on the Internet]. NORDCAN: Cancer Incidence, Mortality, Prevalence and Survival in the Nordic Countries, Version 7.2 (16.12.2015). Association of the Nordic Cancer Registries. Danish Cancer Society. Available from: http:// www.ancr.nu. Accessed February 2, 2016.
Clinical Epidemiology

\section{Publish your work in this journal}

Clinical Epidemiology is an international, peer-reviewed, open access, online journal focusing on disease and drug epidemiology, identification of risk factors and screening procedures to develop optimal preventative initiatives and programs. Specific topics include: diagnosis, prognosis, treatment, screening, prevention, risk factor modification,

Submit your manuscript here: https://www.dovepress.com/clinical-epidemiology-journal

\section{Dovepress}

systematic reviews, risk and safety of medical interventions, epidemiology and biostatistical methods, and evaluation of guidelines, translational medicine, health policies and economic evaluations. The manuscript management system is completely online and includes a very quick and fair peer-review system, which is all easy to use. 